\title{
O perfil e a formação profissional para o Sommelier no Brasil: um estudo preliminar
}

\section{The profile and vocational training for Sommelier in Brazil: a preliminary study}

\author{
Flavia Baratieri Losso (LOSSO, F. B.) ${ }^{*}$ \\ Wilton Carlos Cordeiro (CORDEIRO, W. C. $)^{* *}$
}

RESUMO - Este trabalho apresenta um estudo preliminar referente ao perfil e a formação profissional para o sommelier no Brasil. A pesquisa esteve centrada na identificação e na análise do perfil e formação profissional do sommelier no país, caracterizando seu papel no mercado nacional de vinhos. Para atingir este objetivo foi preciso reunir informações através da pesquisa bibliográfica e documental, assim como, por meio da aplicação de 39 questionários e 2 entrevistas semiestruturadas junto à profissionais deste setor. A área de abrangência da investigação voltou-se para o mercado nacional, muito embora as discussões estejam centradas no mercado regional de Florianópolis (Santa Catarina, Brasil). Este profissional é visto como o responsável pela execução do serviço especializado de vinhos em restaurantes, porém há uma tendência evolutiva para a atuação em lojas especializadas, supermercados, representação comercial, vinícolas através da venda direta ou assessoria. Recémregulamentada no país, a profissão de sommelier apresenta-se em um momento promissor, com crescente reconhecimento e a oferta dos cursos de formação que devem adequar-se às novas necessidades do mercado consumidor.

Palavras-chave: Sommelier; Perfil Profissional; Mercado de Atuação; Formação Profissional.

ABSTRACT - This paper presents a preliminary study regarding the profile and training of sommelier in Brazil. The research was focused on the identification and analysis of the professional profile and training of sommelier in Brazil, as well as its role in the national wine market. In order to achieve this goal it was necessary to gather information through literature and documental research, as well as through 39 questionnaires and 2 semi-structured interviews with such professionals. The area covered by the investigation was the national market, despite much of the discussions was centered in Florianópolis (Santa Catarina, Brazil) local market. This professional is characterized as the responsible for the specialized service of wines in restaurants,

\footnotetext{
* Graduação em Turismo e Hotelaria pela Universidade do Vale do Itajaí (UNIVALI), Especialização em Gestão e Planejamento Turístico e Hoteleiro pela Universidade de Nice-França (UNICE), Mestrado em Turismo e Hotelaria pela Universidade do Vale do Itajaí (UNIVALI), Doutoranda em Geografia no Programa de Pós-Graduação em Geografia da Universidade Federal de Santa Catarina (UFSC). Professora de ensino básico, técnico e tecnológico no Campus Florianópolis - Continente do Instituto Federal de Santa Catarina (IFSC). Endereço para correspondência: Rua da Capela, 1081, Campeche. CEP. 88063-400 - Florianópolis - Santa Catarina (Brasil). Telefone: (48) 3877-8400. Email: flavia@ifsc.edu.br.

** Graduação em Nutrição e Mestrado em Agroecossistemas, pela Universidade Federal de Santa Catarina (UFC). Professor no Instituto Federal de Santa Catarina (IFSC). Endereço para correspondência Rua Amaro Antonio Vieira, 2008. CEP. 88034-101 - Florianópolis - Santa Catarina (Brasil). Telefone: (48) 3334-2349. E-mail: wilton@ifsc.edu.br.
} 
though it has been observed a growing demand for it's placement in specialized stores, supermarkets, brand representation, wineries: performing direct sales or as a consultant. Newly regulated in the country, the sommelier profession presents itself in a promising moment, with growing recognition. The vocational training schools should suit themselves to new demands of this market.

Key words: Sommelier; Professional Profile; Job Market; Vocational Training. 


\section{INTRODUÇÃO}

Atualmente o Brasil apresenta um crescimento importante no panorama mundial do vinho, fato que se reflete nas premiações internacionais conquistadas por diferentes vinícolas brasileiras nos últimos anos (ENOEVENTOS, 2012). Estes resultados são oriundos de um forte movimento de modernização dos vinhedos e do parque industrial vitícola, permitindo o aperfeiçoamento das tradicionais regiões, assim como a consolidação de novas áreas produtoras.

Porém, esta evolução não acontece somente na produção, tem-se identificado que o consumidor brasileiro está bebendo mais vinho, houve um acréscimo no consumo de 9,1\%, entre os anos de 2007 e 2009 (WINE INSTITUTE, 2012). Este aumento no consumo de vinhos é garantido por uma cadeia de lojas e distribuidores que vendem vinhos do mundo todo. Nota-se que o consumidor brasileiro busca se informar cada vez mais sobre a bebida, já que o mercado editorial conta com um acervo variado de revistas, livros e com as infinitas possibilidades oferecidas pelo uso da Internet.

Jones (2006) prevê que no contexto descrito acima, a presença de um profissional qualificado na venda de vinhos torna-se um grande diferencial a favor do sucesso dos empreendimentos que comercializam a bebida, sendo este o trabalho realizado pelo sommelier. Ele é o profissional responsável pelo comércio do vinho em restaurantes, lojas especializadas, adegas, supermercados, entre outros estabelecimentos e sua presença permite ao consumidor escolher com mais segurança um vinho. Segundo o mesmo autor, o mercado consumidor reconhece cada vez mais a importância de seus serviços e aptidões.

Nota-se que as bebidas são os produtos do cardápio de restaurantes que representam maior significado para o setor de serviços de restaurante, além da identificação constante pelo grande interesse dos profissionais e dos alunos durante sua capacitação e atuação profissional. Espera-se que os conhecimentos gerados pelo presente estudo possam se constituir em um importante instrumento para o planejamento de referenciais curriculares que possibilitem o desenvolvimento da qualificação da mão de obra de serviços em restaurantes e bares.

No sentido de justificar esta pesquisa, apontam-se neste artigo possíveis resultados que orientem a construção do perfil de um profissional que se torna a cada 
dia mais presente no ramo de Alimentos \& Bebidas (A\&B). A definição das competências atribuídas a este profissional auxilia, não apenas aos trabalhadores a se sentirem mais seguros quanto a sua qualificação e atuação, como também permite aos empresários do ramo obter maior qualidade dos serviços oferecidos por seus empreendimentos.

A lei $\mathrm{n}^{\mathrm{o}}$ 12.467, de 26 de agosto de 2011, regulamentou a profissão de Sommelier, atendendo ao anseio dos profissionais e das entidades da classe (BRASIL, 2012). A lei prevê as competências do profissional, contudo, o artigo $2^{\circ}$, que regulamentava a formação e capacitação para esta profissão, foi vetado pela Presidência da República (id. ib.), permitindo que indivíduos sem formação específica possam atuar profissionalmente. Percebe-se que, em outros países, a importância da formação profissional é cada vez mais enfatizada através da oferta e do reconhecimento de cursos específicos para o serviço e comércio de vinhos (HAMMOND, 2010), trazendo assim, questionamentos sobre a necessidade de normatização e padronização para estas formações até mesmo no Brasil.

O presente estudo também foi motivado pela regulamentação da profissão, pois se vislumbrou a possibilidade de normatizar esta formação profissional, oferecendo ao consumidor um profissional mais qualificado para auxiliá-lo na escolha do vinho. No intuito de discutir a temática já abordada, esta pesquisa buscou identificar e analisar o perfil e a formação profissional do sommelier no Brasil, caracterizando seu papel no mercado nacional de vinhos.

Desta forma, para atingir com êxito os propósitos deste estudo, optou-se pela realização de uma pesquisa exploratória, de abordagem qualitativa. $\mathrm{O}$ estudo exigiu inicialmente uma revisão bibliográfica sobre o mercado atual de vinhos no Brasil e as características do perfil profissional do sommelier. No intuito de complementar esta fase inicial, utilizou-se a pesquisa documental para obter dados referentes às formações ofertadas especificamente para a capacitação deste profissional no Brasil e em caráter comparativo, se buscou dados sobre modelos de formações ofertadas na Itália, na França e nos Estados Unidos.

Após esta etapa, as informações necessárias para a construção do perfil profissional do sommelier foram obtidas através da aplicação de um questionário padrão. A coleta dos dados deu-se através da abordagem aleatória de 35 profissionais, 
que participavam da $16^{\mathrm{a}}$ edição do Salão Internacional do Vinho - EXPOVINIS Brasil, realizado em São Paulo entre 24 e 26 de abril de 2012. Este evento reúne um contingente bastante diversificado de profissionais da área de vinhos, tornando-se, desta maneira, um campo promissor de pesquisas para o setor (EXPONOR, 2012).

Outro motivo para a escolha da EXPOVINIS Brasil como local de coleta de dados deu-se a partir da dificuldade em se obter informações através de correspondência eletrônica. Inclusive através da Associação Brasileira de Sommeliers - ABS ${ }^{1}$, pois se obteve apenas o retorno de quatro associados, ocasionando um número muito escasso de questionários respondidos. Porém este fenômeno é universal, frequentemente, apenas entre $10 \%$ e $15 \%$ dos questionários enviados são respondidos (GULTEK; DODD; GUYDOSH, 2006).

O questionário era composto de dois momentos distintos, onde a parte inicial visava conhecer as características profissionais do entrevistado, através das seguintes informações: tempo de atuação no setor, instituição onde se formou e carga horária do curso, rendimento médio, entre outros. A segunda parte do questionário objetivava conhecer a visão do profissional sobre a formação e o mercado de trabalho do sommelier. Para isso, as questões abordavam temas como a carga horária ideal para a formação profissional, os conhecimentos primordiais para a qualificação, atividades complementares, o mercado de trabalho no Brasil e as competências relativas aos diferentes campos de atuação.

Tendo como premissa que a construção do perfil profissional do sommelier prevê uma abordagem subjetiva do tema, concentrada no olhar que os indivíduos têm de sua profissão, optou-se por realizar duas entrevistas semiestruturadas com profissionais atuantes no mercado regional de Florianópolis.

\footnotetext{
${ }^{1}$ A Associação Brasileira de Sommeliers - ABS é uma entidade sem fins lucrativos, fundada no Rio de Janeiro em 1983, que tem como objetivo a divulgação do vinho e a propagação de conhecimentos sobre o assunto, através de cursos regulares abertos a profissionais e amadores (ASSOCIAÇÃO BRASILEIRA DE SOMMELIERS RIO DE JANEIRO ABS-RIO, 2012).
} 


\section{O MERCADO DE VINHOS NO BRASIL E A NECESSIDADE DE PROFISSIONALIZAÇÃO}

De acordo com o Instituto Brasileiro do Vinho - IBRAVIN (2012), a vitivinicultura brasileira é uma atividade identificada, principalmente, em nove regiões produtoras do país, representadas pelos estados do Rio Grande do Sul (RS), Santa Catarina (SC), Bahia (BA), Pernambuco (PE), por Minas Gerais (MG), São Paulo (SP) e Paraná (PR). As zonas de clima temperado representam $88 \%$ das áreas de vinhedos e mais de $98 \%$ da uva utilizada para processamento (vinhos, sucos e outros derivados) no país.

As regiões da Serra Gaúcha, no Rio Grande do Sul, do Vale do Rio do Peixe, Planalto Norte e Carbonífera, em Santa Catarina, se destacam como regiões produtoras tradicionais, fato confirmado pela importância destes dois estados no total de vinho produzido no Brasil (BANCO REGIONAL DE DESENVOLVIMENTO DO EXTREMO SUL, 2005).

As estatísticas referentes à produção brasileira sempre estiveram baseadas na produção de vinhos do estado do Rio Grande do Sul, porém, a pesquisa identificou a intenção dos órgãos oficiais em catalogar e demonstrar a totalidade deste setor produtivo. $\mathrm{O}$ quadro 1 demonstra apenas uma estimativa da produção nacional de vinhos de mesa e de vinhos finos ${ }^{2}$ em litros para o ano de 2011.

QUADRO 1 - ESTIMATIVA DA PRODUÇÃO NACIONAL DE VINHOS DE MESA E DE VINHOS FINOS EM LITROS.

\begin{tabular}{|l|c|c|c|}
\hline \multicolumn{1}{|c|}{ Estados } & Vinhos de Mesa & Vinhos Finos & Total da produção \\
\hline Rio Grande do Sul & 257.489 .896 & 51.324 .310 & 308.814 .206 \\
\hline Santa Catarina & 26.000 .000 & 750.000 & 26.750 .000 \\
\hline Pernambuco / Bahia & 2.000 .000 & 6.000 .000 & 8.000 .000 \\
\hline São Paulo & 4.000 .000 & 100.000 & 4.100 .000 \\
\hline Minas Gerais & 3.500 .000 & 10.000 & 3.510 .000 \\
\hline Paraná & 750.000 & 100.000 & 850.000 \\
\hline Total nacional & 293.739 .896 & 58.284 .310 & 352.024 .206 \\
\hline
\end{tabular}

FONTE: CAPELLO, (2011a). Elaborado pelos autores, (2012).

\footnotetext{
${ }^{2}$ Os vinhos de mesa são os vinhos elaborados com as variedades de uvas americanas (não viníferas) e são conhecidos como 'vinhos de garrafão'. Os vinhos finos são os vinhos elaborados com as uvas européias (vitis viníferas), como Chardonnay, Cabernet Sauvignon, Merlot e muitas outras (BANCO REGIONAL DE DESENVOLVIMENTO DO EXTREMO SUL, 2005).
} 
Observa-se que os estados do Rio Grande do Sul e de Santa Catarina representam 95\% da produção nacional de vinhos de mesa e finos do Brasil. Entretanto, esta estimativa foi baseada em dados do Instituto Brasileiro do Vinho - IBRAVIN, safra 2011, das empresas do Rio Grande do Sul, conforme declarações no Cadastro Vinícola chamado de SISDECLARA. Cabe ressaltar que para os demais estados, a estimativa baseou-se em dados compilados de diversas fontes, como, Associação Catarinense dos Produtores de Vinhos Finos de Altitude (ACAVITIS), Empresa de Pesquisa Agropecuária de Minas Gerais (EPAMIG) e através de entrevistas com produtores das respectivas regiões (CAPELLO, 2011a).

A produção brasileira de vinhos está se transformando e se atualizando segundo os critérios de qualidade adotados em regiões produtoras de países do Velho e do Novo Mundo. Cada estado produtor busca sua identidade no mercado, no intuito de se destacar frente à concorrência (LOSSO, 2010). A pesquisa demonstrou que a partir do final da década de 1990 novos investidores surgem no mercado brasileiro de vinhos, como é o caso das empresas que se instalaram nos estados do Paraná, São Paulo, Minas Gerais e Santa Catarina, onde muitas ainda estão por lançar seus vinhos.

Conforme Sato (2009), a Organização Internacional da Vinha e do Vinho - OIV apresenta dados comparativos entre os quinquênios 86/90 e 2001/05 referentes à participação no mercado global de vinhos onde se verificou que os países produtores de vinhos do Novo Mundo (Argentina, Chile, África do Sul, Austrália/Nova Zelândia e Estados Unidos) demonstraram crescimento de $3,1 \%$ para $23,4 \%$, enquanto que os cinco principais países europeus tradicionais produtores (Alemanha, Espanha, Itália, França e Portugal) apresentaram perda de 78,8\% para 64,6\%. Estes dados indicam que está ocorrendo um deslocamento na produção e no consumo mundial para vinhos do Novo Mundo (SATO, 2009), o que fortalece o crescimento do setor produtivo nacional.

Cabe destacar, conforme dados fornecidos pelo Instituto Brasileiro do Vinho IBRAVIN (2012), que da totalidade dos produtos industrializados derivados da uva no Brasil, $77 \%$ são vinhos de mesa e $9 \%$ são sucos de uva, ambos elaborados a partir de uvas de origem americana (Vitis labrusca, Vitis bourquina e híbridos). Aproximadamente $13 \%$ são vinhos finos, elaborados com castas de Vitis vinifera, e $1 \%$ do total representam outros derivados da uva e do vinho. 
A maior parte da produção brasileira de uvas e derivados da uva e do vinho é destinada ao mercado interno, e menos de $1 \%$ dos vinhos produzidos são comercializados fora do país. O Brasil já é considerado uma das melhores regiões no mundo para o cultivo de uvas destinadas a produção de vinhos espumantes, o que permite ao país exportar vinhos para 22 países, como por exemplo, para os Estados Unidos, a Alemanha, a Inglaterra e a República Tcheca (IBRAVIN, 2012).

Embora se perceba a reconfiguração da vitivinicultura brasileira, sua evolução se confunde com o desenvolvimento desta atividade econômica no estado do Rio Grande do Sul que é referência nacional no cultivo de uvas vitis viníferas, na produção de vinhos finos e na capacitação de mão de obra para este setor (LOSSO, 2010).

É importante destacar que foi a partir da década de 1970 que ocorreram os investimentos de grandes empresas estrangeiras na produção de uvas e vinhos no Rio Grande do Sul, ocasionando um significativo aumento na área cultivada com uvas viníferas, destinadas à elaboração de vinhos finos (BANCO REGIONAL DE DESENVOLVIMENTO DO EXTREMO SUL, 2005). O incremento da qualidade e a identidade dos vinhos brasileiros vêm sendo trabalhados deste este período e atualmente o mercado nacional vem ganhando em competitividade (LOSSO, 2010). De acordo com o Instituto Brasileiro do Vinho - IBRAVIN (2012), a venda de vinho nacional cresceu aproximadamente $10 \%$ no ano de 2011 , com significativo consumo dos espumantes nacionais.

De acordo com Capello (2011b), o consumidor brasileiro tem à disposição, entre vinhos nacionais e importados, algo como 40 mil rótulos, de 32 países. Esta diversidade na oferta de vinhos no Brasil é também identificada ao se analisar seu mercado consumidor, que vai desde o consumidor chamado on-trade (conhecedor) até o consumidor off-trade, que consome vinho irregularmente, não acompanha revistas ou sites especializados, compra em supermercados vinhos de até $\mathrm{R} \$ 30,00$ e escolhe sua compra pelo conjunto de suas características, como o país, a uva, a marca conhecida e também pelas promoções.

Ainda segundo Capello (2011b, p. 34), o consumidor on-trade "consome avidamente não só o vinho, mas sua cultura", portanto, o mercado atua também na venda de produtos relacionados ao vinho, como livros, revistas, sites, palestras, eventos, degustações, enoturismo, adegas, acessórios, dentre outros. 
Quanto à reconfiguração da vitivinicultura mundial nota-se que vem ocorrendo desde a década de 1980, motivada por uma série de transformações no processo produtivo, na comercialização e no consumo do vinho marcado por aspectos socioambientais, a partir da segunda metade do século XX, tais como as mudanças nos hábitos alimentares contemporâneos, a introdução de outras bebidas alcoólicas e não alcoólicas à mesa de fiéis consumidores de vinhos, as campanhas antialcoolismo e também, o descrédito quanto à idoneidade de algumas produções vitivinícolas (AGUIAR, 2008).

Particularmente, a abertura comercial do Brasil, a partir da década de 1990, estimulou o consumo de vinhos importados através do aumento de opções de produtos diferenciados em termos de marcas, variedades e denominações de origem (TONIETTO, 2011). Esta situação obriga o produto nacional, em fase de desenvolvimento de marcas e características organolépticas ainda recentes, a disputar o mercado interno de vinhos finos com marcas e produtos já consolidados e reconhecidos pelo consumidor brasileiro (BLUME; HOFF; PEDROZO, 2007).

Surge um novo cenário, no qual emergem consumidores mais exigentes, que buscam conhecer mais sobre a qualidade, a procedência e a diversidade do vinho, tornando este mercado ainda mais competitivo para os vinhos produzidos no Brasil (TONIETTO, 2011).

Apesar dos dados estatísticos do Brasil sobre o consumo do vinho apresentarem uma grande carência de detalhamento, o consumo médio de vinho no Brasil é considerado de 2 litros per capita (CAPELLO, 2011b). Nos grandes centros urbanos do Sul e Sudeste o consumo é mais elevado devido ao maior poder aquisitivo e ao estilo de vida (SATO, 2009), além da constatação de que estes estados tradicionalmente concentram a produção de vinhos do país (LOSSO, 2010) e representam $86 \%$ do consumo total de vinhos (CAPELLO, 2011b). Somente o estado de São Paulo (com 40 milhões de habitantes) consome $33 \%$ do total nacional, enquanto o Rio de Janeiro, estado de maior consumo per capita, apresentando 4,8 litros por habitante, consome $21 \%$ do total nacional. Porém, as regiões Norte, Nordeste e Centro-Oeste ainda consomem meros 0,6 litros per capita ao ano, sendo o maior mercado potencial de crescimento de longo prazo (CAPELLO, 2011b). 
O vinho oferece atualmente no Brasil um mercado amplo e promissor, demonstrando a necessidade de qualificação profissional e novas oportunidades (LOSSO, 2010), seja para o enólogo ou para o sommelier. De maneira resumida, as atribuições do enólogo estão relacionadas à elaboração do vinho. Conforme Schulz (2011) identifica-se no Brasil dois perfis profissionais de enólogos. Na cidade de Flores da Cunha (RS), o mercado de enologia apresenta como foco principal da profissão a elaboração de vinhos de mesa e de sucos, enquanto que no mercado profissional de Bento Gonçalves (RS), o foco principal está na elaboração de vinhos finos. O autor afirma ainda, que no cenário atual, o enólogo exerce mais papéis no negócio vitivinícola, envolvendo-se com rotinas operacionais, como as atividades administrativas e comerciais, o que vem ocasionando um gargalo técnico, já que sua formação profissional ainda não o prepara para estas exigências.

A oferta de formações na área de viticultura e enologia é identificada tanto no nível técnico, quanto no nível superior (tecnologia ou bacharelado), assim como no nível de pós-graduação, como, por exemplo, os cursos de pós-graduação em Fruticultura e Enologia de Alimentos e Bebidas oferecidos pela Universidade do Rio Grande do Sul - UFRGS e de especialização em Agricultura Orgânica ofertado pela Universidade de Caxias do Sul - UCS. No estado do Rio Grande do Sul há a oferta de cursos superiores de viticultura e enologia no IFRS- Instituto Federal de Educação Ciência e Tecnologia de Bento Gonçalves/RS, no Instituto Federal de Educação, Ciência e Tecnologia Sul-rio-grandense, Campus Visconde da Graça e na UNIPAMPA - Universidade Federal do Pampa, Campus Dom Pedrito, já no estado de Pernambuco, o IFPE- Instituto Federal de Educação Ciência e Tecnologia do Sertão Pernambucano Petrolina/PE (ASSOCIAÇÃO BRASILEIRA DE ENOLOGIA, 2012).

Nas principais capitais do Brasil e num mercado que cresce em exigência, o papel de um sommelier qualificado e com uma formação adequada será cada vez mais uma necessidade fundamental para a comercialização do vinho. A recente regulamentação desta profissão demonstra esta demanda por mais profissionalismo, porém o sommelier deve manter-se atualizado e complementar sua formação com o estudo de história, idiomas e investindo em sua cultura geral (RUSSO, 2011).

O crescente consumo de vinhos no Brasil implica na contratação de um profissional especializado para os restaurantes, capaz de atender estes novos 
consumidores com excelência e profissionalismo. De acordo com Vaccarini (2005), até o final do século XIX, o sommelier era um profissional encontrado principalmente na hotelaria de luxo. Atualmente é possível encontrá-lo também em diversos tipos de restaurantes e ainda em outros tipos de empresas, como wine bar, enotecas, importadoras e distribuidoras de bebidas, o que resultou no desenvolvimento de novas competências profissionais. Como o sommelier é "o profissional que aconselha a clientela a respeito da escolha das bebidas e cuida do serviço" (CALÓ et al., 2004), sua atuação junto ao mercado consumidor é fundamental para o fortalecimento do setor produtivo de vinhos.

\section{A PROFISSÃO SOMMELIER E AS QUALIFICAÇÕES PARA O MERCADO DE TRABALHO}

O sommelier é um profissional que executa o serviço especializado de vinhos nos mais diversos segmentos, desde em eventos gastronômicos em salões, restaurantes e hotéis, inclusive nos supermercados, lojas especializadas e até em companhias aéreas e marítimas (JONES, 2006).

Paulino (2009) descreve que as funções e atividades desenvolvidas pelo sommelier exigem que ele participe de todas as fases do planejamento e organização do consumo do vinho. O autor afirma que dentre suas funções está a seleção do produto, considerando as quantidades e qualidades a serem adquiridas, zelando pelo armazenamento correto nas adegas. Entretanto, a função mais destacada para este profissional é o trabalho no salão, que se inicia com a criação da carta de vinhos e culmina no serviço à mesa.

O sommelier é uma fonte segura, no momento em que o cliente escolhe o vinho no restaurante. As informações precisas sobre as características do produto e a sugestão de harmonizações com pratos criam um clima amistoso, com benefícios para o profissional e para o cliente. O sommelier desempenha um papel importante na educação de novos profissionais, sem perder de vista a contribuição para a formação de consumidores mais conscientes (GULTEK, DODD e GUYDOSH, 2006; HAMMOND, 2010). 
Vaccarini (2005) demonstra que a palavra sommelier originou-se na Idade Média, no período do Renascimento, a partir do nome dos serviçais responsáveis pelo serviço de bebidas aos membros da aristocracia. $O$ autor menciona que estes personagens eram chamados de sommiers, pois os seus utensílios eram carregados em fardos denominados de somme. Também comenta que a expressão evoluiu para sommeliers, chegando à atual denominação. $\mathrm{O}$ autor chama a atenção para o fato de que inicialmente esta atividade era realizada por escravos, porém mais tarde, membros de castas mais baixas da nobreza compravam a primazia de servir às classes mais altas, dessa forma poderiam obter favores. Coloca que cabia a este indivíduo experimentar tudo que o rei fosse ingerir, desde alimentos até bebidas, para evitar que o monarca fosse envenenado.

Por sua vez, referente à evolução desta atividade enquanto profissão tem-se o artigo $3^{\circ}$ da Lei $\mathrm{N}^{\circ} 12.467$, de 26 de agosto de 2011 (BRASIL, 2012) que dispõe sobre a regulamentação do exercício da profissão de sommelier, define que são atividades específicas deste profissional: 1) participar no planejamento e na organização do serviço de vinhos em empresas de eventos gastronômicos, hotelaria, restaurantes, supermercados e enotecas e em comissariaria de companhias aéreas e marítimas; 2) assegurar a gestão do aprovisionamento e armazenagem dos produtos relacionados ao serviço de vinhos; 3) preparar e executar o serviço de vinhos; 4) atender e resolver reclamações de clientes, aconselhando e informando sobre as características do produto; e por fim, 5) ensinar em cursos básicos e avançados de profissionais sommelier (BRASIL, 2012).

Vinculando-se a isso, através deste estudo foi possível identificar no Brasil a oferta de diversos cursos de qualificação profissional para a função de sommelier, principalmente nas regiões Sul e Sudeste. Como ainda não há uma diretriz nacional regulando a oferta destas capacitações, se observa algumas variações de carga horária, conhecimentos, competências e habilidades mínimas e também, parcerias importantes entre escolas e associações representativas do Brasil com instituições e órgãos representativos de países como a Itália e a França.

No Brasil, a Associação Brasileira de Sommeliers (ABS), através de suas sucursais, é a principal referência na oferta de cursos para as diversas regiões do país. Outras entidades promovem cursos com frequência, como o Serviço Nacional do 
Comércio (SENAC), a Escola de Gastronomia da UCS-ICIF (Universidade de Caxias do Sul - Italian Culinary Institute for Foreigners) e o Instituto Federal de Santa Catarina (IFSC).

De maneira geral, estas qualificações são ofertadas em módulos e, por exemplo, a Escola de Gastronomia da UCS-ICIF oferece um curso básico de sommelier internacional $^{3}$ com duração de seis dias (55 horas-aula) que permite ingressar em um programa de formação de qualificação de sommelier profissional, com duração de 300 horas-aula e dividido em nove módulos (ESCOLA DE GASTRONOMIA UCS-ICIF, 2011).

A Associação Brasileira de Sommeliers (ABS), filiada à Association de la Sommelerie Internationale, vem ofertando uma "Formação de Profissionais" dirigida a quem já trabalha ou pretende trabalhar no mercado de vinhos, como sommelier profissional ou consultor/assessor. A formação é dividida em 3 módulos: Módulo 1 Fundamentos do vinho; Módulo 2 - Países; e Módulo 3 - Serviço (ASSOCIAÇÃO BRASILEIRA DE SOMMELIER SÃO PAULO ABS-SP, 2011).

A pesquisa confirmou que o Instituto Federal de Santa Catarina (IFSC) está ofertando uma qualificação de 160 horas-aulas intitulada de Formação Inicial e Continuada em Aperfeiçoamento no Serviço de Vinhos com o objetivo geral de propiciar o aprimoramento dos profissionais do setor de restauração no serviço de vinhos. Cabe destacar que há oferta de outras formações na instituição e que estas são compostas por disciplinas que apresentam como conteúdo programático o estudo dos vinhos e a harmonização com os cardápios de comidas.

As formações de gastronomia ofertadas no Brasil, seja um curso superior de tecnologia ou bacharelado, normalmente apresentam em seus currículos disciplinas de enologia ou enogastronomia ou harmonização de vinhos e comidas, conforme discussões de diretrizes curriculares desenvolvidas para esta área. Neste estudo optou-se por concentrar as discussões junto às formações e certificações que se apresentam com objetivos, competências ou ementas diretamente relacionadas ao profissional sommelier.

Portanto, quanto ao currículo dos cursos, assim como a carga horária, identificou-se grande variação. Entretanto, alguns temas formam a espinha dorsal da

\footnotetext{
${ }^{3}$ Este curso é certificado pela Federação Italiana de Sommelier - FISAR que é uma associação estrangeira com o reconhecimento para a certificação de Sommelier Básico Internacional, Sommelier Profissional e Degustador de Vinhos (ESCOLA DE GASTRONOMIA UCS-ICIF, 2011).
} 
formação do profissional, como as noções de viticultura, a relação da videira com a terra, a elaboração dos diferentes tipos de vinhos, além de um olhar dedicado às diferentes regiões produtoras de vinhos no mundo. Nota-se que as práticas de serviço de vinhos à mesa e as técnicas de venda junto ao cliente são conteúdos integrantes destas formações, fato também evidenciado por Paulino (2009).

No intuito de ampliar as discussões em torno das formações e certificações possíveis e mais adequadas ao perfil profissional do sommelier, buscou-se apresentar alguns exemplos da França, Estados Unidos e Itália.

Através de uma rápida busca na Internet é possível identificar diversas entidades envolvidas com a formação de sommeliers nos Estados Unidos. Há uma concentração entre São Francisco e Nova Iorque, porém a North American Sommelier Association (NASA) está presente em cinco estados e é a única instituição filiada à Worldwide Sommelier Association (WSA). Estas instituições atuam na formação de sommeliers através de seus cursos, mas também exercem o papel de certificadoras da profissão (US SOMMELIER ASSOCIATION, 2012). O curso ofertado pela WSA, por exemplo, é pautado no método da Associazione Italiana Sommelier e está dividido em três módulos, Viticultura e Enologia, Enografia (descrição científica dos vinhos do mundo e das suas propriedades) e Harmonização de vinhos e comidas (NORTH AMERICAN SOMELLIER ASSOCIATION, 2012). Os cursos citados possuem duração média de seis semanas, com encontros de 3 horas (US SOMMELIER ASSOCIATION, 2012).

A Itália possui uma forte tradição na profissão de sommelier, haja vista que das 13 edições do concurso do melhor Sommelier do mundo, promovido pela Association de La Sommelerie Internationale (ASI), três foram vencidos por italianos, seis por franceses e os demais distribuídos entre Japão, Dinamarca, Suécia e Inglaterra (VACCARINI, 2005, p. 224). A formação do profissional sommelier na Itália é orquestrada por duas instituições distintas, a Federazione Italiana Sommelier (FISAR) e a Associazione Italiana Sommelier (AIS). As duas entidades possuem um esquema de formação semelhante, composto por três níveis. O primeiro nível representa a base da profissão sendo constituído pelos conhecimentos de viticultura, enologia, técnicas de degustação e de serviço de vinhos e bebidas. O segundo nível está focado no conhecimento dos vinhos italianos e estrangeiros. No terceiro nível são trabalhados os 
saberes relacionados à harmonização entre vinhos e alimentos (ASSOCIAZIONE ITALIANA SOMMELIERS, 2012).

Já as escolas profissionais de hotelaria e gastronomia da França possuem reconhecimento internacional e estão estruturadas a partir de diretrizes curriculares nacionais estabelecidas a partir de comissões mistas compostas por membros do Ministério da Educação, das escolas de hotelaria e gastronomia e profissionais atuantes destas áreas (FRANCE, 2012). Existe a oferta de uma certificação específica para a profissão de sommelier onde o aluno é capacitado para comprar, armazenar, gerenciar os estoques, as vendas e os serviços de vinhos e outras bebidas. É importante destacar que este diploma é ofertado aos alunos que cursaram formações técnicas e tecnológicas em hotelaria e gastronomia, assim como aos profissionais que comprovem mais de três de experiência na área de sommellerie (L'HÔTELLERIE RESTAURATION, 2012).

Rabachino (2008) refere-se ao profissional como "sommelier internacional" e destaca que deve possuir o certificado de qualificação de um curso relativo às técnicas de degustação, reconhecido e emitido por órgão competente. Ao abordar as atribuições principais, o autor citado evidencia a importância do conhecimento sobre as principais regras de etiqueta relativas à mise-en-place e às técnicas de serviço. Na área de restauração, interage diretamente com o público, tendo como atribuições principais a escolha do copo adequado, a correta temperatura de serviço e a sucessão de vinhos à mesa, harmonizando-os com a comida servida (CÂNDIDO; VIEIRA, 2002).

Conforme Jones e Dewald (2006, p. 3), na apresentação de dados de suas pesquisas, foi possível perceber que:

[...] a formação do pessoal de serviço dá credibilidade à venda adaptativa ou persuasiva e como isso pode afetar as vendas de vinho. Eles concluíram que o conhecimento do vinho é importante, mas que a habilidade em vender também é crucial, para aumentar as vendas de vinho.

Além disso, o profissional deve estar constantemente se atualizando através de viagens, mantendo contato com produtores e fornecedores, participar de degustações, feiras de vinhos, entre outras atividades complementares a sua capacitação (GULTEK; DODD; GUYDOSH, 2006).

O mercado de atuação para o sommelier é bem diversificado, pensa-se logo em um restaurante, mas as possibilidades são muitas. O profissional pode atuar em lojas especializadas e supermercados auxiliando o consumidor nas suas escolhas. Em meios 
de hospedagem, o sommelier é responsável pela adega. Seu trabalho em uma vinícola possui um caráter receptivo, traduzindo aos visitantes o trabalho que o enólogo realiza (ASSOCIATION DE LA SOMMELLERIE INTERNATIONALE, 2009).

Vinculando-se a esse assunto, o perfil dos sommeliers que responderam ao questionário desta investigação via email em dezembro de 2011 e durante a EXPOVINIS Brasil em abril de 2012 apresentou as seguintes características: predominantemente do gênero masculino (27 entrevistados); idade bastante variada, com uma leve tendência à faixa entre 18 e 30 anos (10 entrevistados). A maioria com nível superior completo, sendo que 12 entrevistados mencionaram possuir também o diploma de pós-graduação em diferentes áreas. A formação específica de sommelier foi apontada no currículo de 23 dos profissionais entrevistados, com cursos de média duração, variando entre 100 e 300 horas, onde 10 dentre eles obtiveram sua certificação pela Associação Brasileira de Sommelier São Paulo (ABS-SP). Os entrevistados mencionaram atuar na profissão há mais de cinco anos e há menos de dez anos, trabalhando em diferentes áreas que incluem: ensino, consultoria, importadoras, lojas especializadas e vinícolas. Somente três dos sommeliers entrevistados disseram trabalhar atualmente em restaurantes. O rendimento médio destes profissionais foi bem diversificado, girando em torno de três e seis salários mínimo. A maioria afirmou que, a remuneração ainda não é condizente com a qualidade e amplitude da formação profissional que tiveram.

Os entrevistados afirmaram ser necessária uma formação específica para exercer a profissão (29 entrevistados) e que esta deveria ser de nível técnico, apresentando uma carga horária entre 300 e 600 horas. Os conhecimentos citados como mais importantes para a formação profissional, em ordem de importância, foram: harmonização de comidas e bebidas, enologia, carta de vinhos e outras bebidas, geografia vitivinícola, análise sensorial, técnicas de vendas e controle de estoques.

Os entrevistados foram unanimes quanto à importância do ensino de uma língua estrangeira como parte da formação do profissional, sendo que o inglês foi apontado por todos como primeira língua estrangeira para esta profissão. Para os entrevistados, a formação do profissional deve ser complementada por outras atividades, tais como: viagens a regiões vitivinícolas, degustações de vinhos, harmonização com comidas e a experiência profissional. 
Foi também apontado que o profissional deve possuir as seguintes características: paladar apurado, organização e disciplina, curiosidade e espírito inovador, bom relacionamento interpessoal e boa apresentação pessoal.

Quanto ao mercado de trabalho, foram citadas diversas possibilidades, com ênfase em lojas especializadas em vinhos e bebidas, hotéis e importadoras de vinhos, além de atividades como, vinícolas, personal sommelier, cruzeiros, consultoria, imprensa, eventos e supermercados. Novamente destaca-se $o$ fato de poucos referenciarem os restaurantes como área principal de atuação para o sommelier, contradizendo os referenciais teóricos pesquisados na fase inicial deste estudo.

No sentido de melhor apreender as questões definidas por esta pesquisa, foram entrevistados, durante o mês de abril de 2012, dois profissionais com formação de sommelier e que estavam atuando ${ }^{4}$ de maneira diversa no mercado regional de Florianópolis. Ambos destacaram a importância do crescente mercado consumidor local, especialmente nos últimos anos, evidenciado inclusive na maior e melhor oferta de vinhos nacionais após o ano de 2000.

Através das entrevistas observou-se a pouca atuação de sommeliers em restaurantes na cidade de Florianópolis. Este fato pode ser explicado, em parte, como resultado da ausência de uma política de valorização de profissionais qualificados pelos restaurantes da região. Os entrevistados confirmaram a tendência sobre o mercado de atuação deste profissional, pois a maioria informou exercer suas funções como consultor ou em lojas especializadas e supermercados. Muitos destes profissionais mencionaram atuar como instrutores em cursos básicos de vinhos, porém, relataram que os participantes destes cursos são os consumidores finais (enófilos) e não os trabalhadores do setor.

Tanto nos questionários quanto nas entrevistas, evidenciou-se a dificuldade da maioria dos participantes no entendimento referente às modalidades e aos níveis de ensino, o que impõe aos pesquisadores realizar uma discussão aprofundada em um novo momento deste estudo, assim como a coleta de novos dados através da aplicação de mais algumas entrevistas semiestruturadas. Porém, a pesquisa apontou para a

\footnotetext{
${ }^{4}$ Um dos entrevistados mencionou estar atuando no comércio de vinhos da região de Florianópolis há 17 anos, sendo proprietário de uma loja especializada e contribuindo para a evolução dos parâmetros atuais identificados no mercado consumidor regional. O segundo entrevistado mencionou atuar na área de alimentação possuindo um programa na televisão local, além de escrever para livros e revistas sobre o tema.
} 
necessidade de oferta de cursos de nível técnico, que possa abarcar os trabalhadores do setor de comércio de vinhos e de restaurantes por meio de um curso acessível (gratuitos ou com preços mais baixos) e que as aulas não ocorram em todos os dias da semana, apontando, em uma das entrevistas, para o modelo semipresencial.

Os entrevistados demonstraram reconhecer que o mercado de trabalho ainda necessita aceitar melhor a importância da qualificação e capacitação profissional, mas afirmaram que seria inevitável, já que os consumidores estão cada vez mais informados e são as pessoas que podem pagar pelos cursos presentes na oferta nacional.

Cabe destacar que ambos afirmaram que somente a capacitação não bastaria para a formação deste profissional, que é preciso manter-se informado sobre o mercado de vinhos e de alimentação, estudar línguas, com destaque para o inglês e ampliar seus conhecimentos gerais.

Diante do que foi pesquisado, é importante ressaltar que o papel do sommelier é de complementar e valorizar o produto elaborado pelo enólogo. Onde termina o trabalho da produção do vinho, inicia o trabalho do sommelier, no sentido de aconselhar a melhor escolha do vinho respeitando as preferências do consumidor.

\section{CONSIDERAÇÕES FINAIS}

O presente trabalho buscou identificar e analisar o perfil e a formação profissional do sommelier no Brasil, caracterizando seu papel no mercado nacional de vinhos.

É possível afirmar, segundo os diferentes autores estudados, que este profissional é o especialista dos vinhos, dos destilados, licores e dos espumantes e atua tradicionalmente em restaurantes gastronômicos e em grandes hotéis de luxo. Ele aconselha a clientela e responsabiliza-se pelo serviço destas bebidas, ocupando-se igualmente da gestão da adega e do planejamento da carta de vinhos. Porém, a investigação trouxe uma nova tendência para o mercado de atuação deste profissional, já que a maioria dos entrevistados evidenciou o trabalho especializado em lojas de bebidas, importadoras e supermercados, bem como destacaram o desempenho em assessorias e consultorias. 
Quanto ao perfil dos profissionais entrevistados, tanto nos questionários quanto por meio das entrevistadas semiestruturadas, chamou a atenção que a maioria contava com nível superior completo, inclusive com pós-graduação. Supõe-se que esse fato pode apresentar diversas explicações, entre elas que a profissão desperta interesse e está atraindo profissionais de outras áreas ou que os custos da formação só estão disponíveis para indivíduos economicamente bem estabelecidos. De qualquer forma, o fenômeno precisa ser mais bem estudado e aprofundado.

$\mathrm{O}$ veto ao artigo $2^{\circ}$ da lei que regulamenta a profissão de sommelier (que normatizava a oferta das formações e cursos) caracteriza-se, na opinião dos presentes autores, como uma interpretação de certa forma desalinhada ao processo de qualificação profissional no país, além de abrir as portas à atuação de pessoas sem formação específica. Isso, pois há mais de uma década, o governo federal tem criado programas direcionados à formação e qualificação profissional (Programa Nacional de Acesso ao Ensino Técnico e Emprego - PRONATEC e a Rede Nacional de Certificação Profissional e Formação Inicial e Continuada - CERTIFIC), além de investir na expansão dos institutos federais, cuja missão é exatamente promover a formação técnica e tecnológica nos mais diversos níveis de educação.

Um dado relevante apontado na bibliografia e confirmado nas entrevistas, é que a formação de sommelier se dá em nível técnico. Isso pode ser observado na estrutura de ensino ofertada pela França e pelos Estados Unidos (FRANCE, 2012; GULTEK, DODD, GUYDOSH, 2006). Além de ter sido reforçado pela sugestão de carga horária dos cursos, entre 300 e 600 horas e pelas informações obtidas através das entrevistas.

No Brasil não há um padrão para a formação do profissional sommelier, fato recorrente nas formações do eixo profissional Turismo, Hospitalidade e Lazer. Portanto, recomenda-se um estudo sobre os currículos dos diferentes formadores e a busca por um consenso em termos de carga horária mínima, componentes curriculares, competências gerais e habilidades profissionais para os cursos e a certificação de Sommellerie, no sentido de incentivar a valorização da educação profissional e de obter o reconhecimento da qualificação deste profissional pelo mercado de trabalho. 


\section{REFERÊNCIAS}

AGUIAR, M. O vinho na era da técnica e da informação: um estudo sobre Brasil e Argentina. Belo Horizonte: Autêntica, 2008.

ASSOCIAÇÃO BRASILEIRA DE ENOLOGIA (ABE). Faculdade de Enologia. Disponível em: <http://www.enologia.org.br/referencias/faculdades-de-enologia>. Acesso em: 25/10/2012.

ASSOCIAÇÃO BRASILEIRA DE SOMMELIER RIO DE JANEIRO (ABS-RIO). Disponível em: <http://www.abs-rio.com.br/index.asp>. Acesso em: 24/10/2012.

ASSOCIAÇÃO BRASILEIRA DE SOMMELIER SÃO PAULO (ABS-SP). Disponível em: <http://www.abs-sp.com.br/conteudo/page_cont_1.asp>. Acesso em: 15/12/2011.

ASSOCIATION DE LA SOMMELERIE INTERNATIONALE (ASI). Sommelier, Profissão do Futuro. Rio de Janeiro: Senac, 2009.

ASSOCIAZIONE ITALIANA SOMMELIERS (AIS). Disponível em: <http://www.aisitalia.it/area-formazione.aspx\#.UP8ve2fwy2U>. Acesso em: 20/11/2012.

BANCO REGIONAL DE DESENVOLVIMENTO DO EXTREMO SUL - BRDE (Florianópolis). Vitivinicultura em Santa Catarina: situação atual e perspectivas. Florianópolis: BRDE, 2005. 83 p.

BLUME, R.; HOFF, D. N.; PEDROZO, E. A. Potencialidade competitiva e recursos essenciais à produção de vinhos finos: um estudo da vitivinicultura em São Joaquim, SC. In: XLV CONGRESSO BRASILEIRO DE ECONOMIA E SOCIOLOGIA RURAL, 2007, Londrina. Anais... Londrina: SOBER, 2007.

BRASIL, Presidência da República. Disponível em: <http://www.planalto.gov.br/ccivil_03/_Ato2011-2014/2011/Lei/L12467.htm>. Acesso em: 07/05/2012.

CAlÓ, A.; CERNIlli, D.; LANATI, D.; MARTELli, G.; SABELliCO, M.; SCIENZA, A.; VACCARINI, G. Vinho: escolha, compra, serviço e degustação: manual do sommelier. São Paulo: Globo, 2004.

CÂNDIDO, I.; VIERA, E. V. de. Maître d'hôtel: técnicas de serviço. Caxias do Sul: Educs, 2002.

CAPELLO, M. Raio-X da atual produção vinícola brasileira. Revista Anuário Vinho do Brasil. Rio de Janeiro, p. 28-31, 2011a. Edição especial.

Brasil, o gigante acordou. Revista Anuário Vinho do Brasil. Rio de Janeiro, p. 32-34, 2011b. Edição especial. 
ENOEVENTOS. Disponível em:

<http://www.enoeventos.com.br/colunistas/marcelo/marcelo058.htm>. Acesso em: 24/10/2012.

ESCOLA DE GASTRONOMIA UCS-ICIF. Disponível em: <http://www.ucs.br/site/ucs/tplEscolaGastronomiaNova/extensao/escola_de_gastronomi a/aperfeicoamento\#sommelerie>. Acesso em: 15/12/2011.

EXPONOR. Disponível em: <http://www.exponor.com.br/expovinis/o_evento/>. Acesso em: 24/10/2012.

FRANCE, Centre de ressources nationales hotellerie restauration (CRNHR). Disponível em: <http://www.hotellerie-restauration.ac-versailles.fr/spip.php?article91>. Acesso em: 10/04/2012.

GULTEK, M. M.; DODD, T. H.; GUYDOSH, R. M. Attitudes towards wine-service training and its influence on restaurant wine sales. International Journal of Hospitality Management. Orlando, n. 25, Issue 3, p. 432-446, 2006, september.

HAMMOND, R. M. S. Effects of experience, knowledge, and processing style on information used by restaurant wine consumers. A dissertation in Hospitality Administration, Submitted to the Graduate Faculty of Texas Tech University in Partial Fulfillment of the Requirements for the Degree of Doctor of Philosophy, 2010.

INSTITUTO BRASILEIRO DO VINHO (IBRAVIN). Disponível em: <http://www.ibravin.org.br/regioesprodutoras.php>. Acesso em: 12/04/2012.

JONES, M; DEWALD, B. Sommeliers' Role and Influence as a Wine Marketer in the United States. $3^{\circ}$ INTERNATIONAL WINE BUSSINES RESEARCH CONFERENCE, Montpellier, 6-7-8 July, 2006.

L'HÔTELLERIE RESTAURATION. Écoles hôtelières et formation en hôtellerie restauration. Disponível em: <http://www.lhotellerie-restauration.fr/ecoleformation/diplomes/mc-sommellerie.asp >. Acesso em: 19/11/2012.

LOSSO, F. B. A produção de vinhos finos de altitude na região vitivinícola de São Joaquim (SC): uma alternativa para o turismo? Dissertação (Mestrado). Programa de Pós-graduação em Turismo e Hotelaria. UNIVALI. Balneário Camboriú: 2010. 206 p.

NORTH AMERICAN SOMELLIER ASSOCIATION - NASA. Certified Sommelier. Disponível em: <http://www.nasommelier.com/courses/certified-sommelier/>. Acesso em: 20/11/2012.

PAULINO, Cristiano M. P. Caracterização da gestão de vinhos nos restaurantes do segmento médio alto: uma abordagem integrada. Dissertação (Mestrado). Programa de Pós-graduação em Gestão Comercial. Faculdade de Economia da Universidade do Porto. Porto: 2009. 
RUSSO, D. A serviço do vinho. Revista Anuário Vinho do Brasil. Rio de Janeiro, p. 94. 2011. Edição especial.

SATO, G. S. O consumo de vinho no Brasil. Revista brasileira de viticultura e enologia. Bento Gonçalves, n. 1, p. 10-17. Outubro, 2009.

SHULZ, M. R. Disponível em: <http://www.enologia.org.br>. Acesso em: 10/12/2011.

TONIETTO, J. Disponível em:

<http://sistemasdeproducao.cnptia.embrapa.br/FontesHTML/Uva/UvasViniferasRegioe sClimaTemperado/indicacoes.htm>. Acesso em: 20/11/2011.

US SOMMELIER ASSOCIATION. Disponível em:

$<$ http://www.ussommelier.com/index.php?option=com_content\&view=category\&layou $\mathrm{t}=$ blog\&id=4\&Itemid=7>. Acesso: $20 / 11 / 2012$.

VACCARINI, G. Manuale del Sommelier: come conoscere, apprezzare, valutare Il vino e come gestire uma cantina. Firenze - Milano: Giunti Editore S. p. A., 2005.

WINE INSTITUTE. Disponível em:

$<$ http://www.wineinstitute.org/files/2010_Per_Capita_Wine_Consumption_by_Country. pdf $>$. Acesso em: 10/05/2012.

Recebido em: 01-07-2012.

Aprovado em: 01-08-2012. 